\title{
Clinical Course of Hyperprolactinemia in Children and Adolescents: A Review of 21 Cases
}

\author{
Erdal Eren1, Şenay Yapıcı2, Esra Deniz Papatya Çakır2, Latife Aytekin Ceylan², Halil Sağlam¹, Ömer Tarım¹ \\ ${ }^{1}$ Department of Pediatric Endocrinology, Uludağ University, Faculty of Medicine, Bursa, Turkey \\ ${ }^{2}$ Department of Pediatrics, Uludağ University, Faculty of Medicine, Bursa, Turkey
}

\begin{abstract}
Objective: Hyperprolactinemia may be due to various etiological factors and may present with different signs and symptoms. It is relatively less frequent in childhood than in adulthood. The aim of this study was to evaluate retrospectively the clinical course and outcome of hyperprolactinemia in pediatric patients.

Methods: We investigated the records of 21 patients with hyperprolactinemia who attended a tertiary hospital.

Results: Menstrual problems, galactorrhea, and headache were the most common presenting symptoms. Hyperprolactinemia was due to microadenoma in 10, macroadenoma in 7 , and was drug-induced in 4 patients. Bromocriptine and cabergoline were equally effective in lowering serum prolactin levels. Surgical treatment in children with macroprolactinoma was not curative and dopamine agonist therapy was required postoperatively.

Conclusion: In the presence of any clinical symptom or sign suggestive of suppression of the pituitary-gonadal axis, hyperprolactinemia should not be forgotten as a probable diagnosis. Medical therapy seems effective in microadenoma. Surgical therapy may not be successful in macroadenoma and recurrence is frequent.
\end{abstract}

Key words: Prolactin, puberty, prolactinoma, pituitary

Conflict of interest: None declared

Received: 19.02.2011
Accepted: 17.03.2011

\section{Introduction}

A variety of etiological factors including disorders of the hypothalamo-pituitary axis, interruption of dopamine synthesis, stress, pituitary tumors, polycystic ovary syndrome, primary hypothyroidism, and various medications may lead to hyperprolactinemia (1). Hyperprolactinemia in girls causes delayed puberty, hypogonadotropic hypogonadism, primary or secondary amenorrhea, and galactorrhea (2). The clinical åpicture in boys includes delayed puberty, gynecomastia, and galactorrhea as well as neuro-ophthalmologic findings such as impaired vision and headache due to a higher frequency of macroadenomas (3). Prolactinoma is the most common hormonally active pituitary adenoma which usually presents in adulthood (4). Therefore, epidemiologic and clinical data in children are limited. In this investigation, we aimed to determine the etiology, clinical findings, and management of hyperprolactinemia in children and adolescents at a tertiary hospital.

\section{Materials and Methods}

A total of 21 patients with hyperprolactinemia, followed in Uludağ University Division of Pediatric Endocrinology between July 2006 and July 2010, were studied retrospectively. The presenting symptoms, associated diseases, medications, physical and laboratory findings were recorded. The serum levels of prolactin, follicle-stimulating hormone (FSH), luteinizing hormone (LH), estradiol (E2), testosterone (T), thyrotropin (TSH), and free thyroxine $\left(\mathrm{fT}_{4}\right)$ were measured by the Architect device

\section{Address for Correspondence}

Ömer Tarım MD, Uludag University, Medical Faculty, Department of Pediatric Endocrinology, Bursa, Turkey

Tel.: +90 2242950401 Fax: +90 2244428143 E-mail: drotarim@gmail.com

(๑) Journal of Clinical Research in Pediatric Endocrinology, Published by Galenos Publishing. 
using chemiluminescent microparticle enzyme immunoassay. A prolactin level of $5-20 \mathrm{ng} / \mathrm{mL}$ was considered normal in both sexes. A level above $20 \mathrm{ng} / \mathrm{mL}$ in two successive measurements was defined as hyperprolactinemia (5). Magnetic resonance imaging (MRI) of the pituitary gland was performed in all patients. A pituitary adenoma with a diameter of less than $1 \mathrm{~cm}$ was defined as microadenoma and one above $1 \mathrm{~cm}$ in diameter as macroadenoma. Patients with macroadenoma underwent transsphenoidal pituitary surgery. Medical treatment was given to the subjects with microadenoma, persistent postoperative hyperprolactinemia, and to those with hyperprolactinemia due to medications. Bromocriptine $2.5 \mathrm{mg}$ (Parlode ${ }^{\circledR}$, Novartis) once or twice a day or cabergoline $0.5 \mathrm{mg}$ (Dostinex ${ }^{\circledR}$, Pharmacia) once or twice a week was given as prolactin-lowering drug. Bromocriptine or cabergoline was selected randomly and according to the availability of the medicine in the market. Serum prolactin levels were monitored at 2-4 weeks after the initiation of treatment and 3-6 months thereafter.

Table 1. Auxological data of the hyperprolactinemia patients (mean values)

\begin{tabular}{ll}
\hline Gender & $\mathbf{1 7}$ females $(\mathbf{8 1 \% )}, \mathbf{4}$ males $(\mathbf{1 9 \%})$ \\
\hline Age (years) & $15.0 \pm 2.7(7.4-17.9)$ \\
Total group & $12.9 \pm 3.2$ \\
Males & $15.5 \pm 2.4$ \\
Females & $-0.4 \pm 1.5(-3.4-2.4)$ \\
Height SDS & $0.3 \pm 1.3(-3.9-2.1)$ \\
Weight SDS & $22.6 \pm 4.9(13.4-34.6)$ \\
BMI & $0.5 \pm 1.2(-3.6-2.2)$ \\
BMI SDS &
\end{tabular}

Table 2. Mean prolactin levels of the hyperprolactinemia patients

Prolactin levels $(\mathrm{ng} / \mathrm{mL})$

\begin{tabular}{ll}
\hline Total group & $460.9 \pm 669$ \\
Females & $259.3 \pm 394.8$ \\
Males & $1318 \pm 971.3^{*}$ \\
Patients with microadenoma (10 cases) & $259.3 \pm 394.8$ \\
Patients with macroadenoma (7 cases) & $1.118 .6 \pm 843.6 * *$ \\
Patients on antipsychotic medication ( 4 cases) & $147.4 \pm 57.2 * * *$ \\
\hline * Statistical significance between genders $\mathrm{p}=0.002$ & \\
$\begin{array}{l}\text { ** Statistical significance between microadenoma and macroadenoma cases } \\
\text { (p=0.024) }\end{array}$ \\
$\begin{array}{l}* * \text { Statistical significance between microadenoma cases and those on antipsyc } \\
\text { hotic }\end{array}$
\end{tabular}

Mann-Whitney $U$ test was used to compare groups for continuous variables, and Fisher's exact test was used for categorical variables. A p value of less than 0.05 was considered significant. SPSS 16.0 statistics program was used for analysis.

\section{Results}

A total of 21 patients [17 girls (81\%) and 4 boys (19\%)] with hyperprolactinemia were included in the study. Mean age at diagnosis and anthropometric data are presented in Table 1 . The presenting symptoms in the female patients were irregular menstruation in 9, galactorrhea in 6 , headache in 3 , and primary amenorrhea in 4 . Three patients were asymptomatic, two of whom were receiving antipsychotic medication. Among males, headache was the presenting symptom in 2, gynecomastia in 1, galactorrhea in 1 , and blurred vision in 1 . One patient was diagnosed based on an elevated prolactin level in a random blood sample and turned out to have a macroadenoma. None of the patients had papilledema at fundoscopic examination. Mean prolactin levels are summarized in Table 2 and the clinical course and prolactin levels of individual patients are given in detail in Table 3a and 3b.

The initial serum levels of FSH, LH, E2, T, TSH, and $\mathrm{fT}_{4}$ were within normal ranges and did not show any significant changes after treatment (data not presented). All male patients had macroadenoma and underwent surgical resection. None of the patients had post-surgical visual problems. Prolactinoma was histopathologically confirmed in all surgical specimens. The serum prolactin level was significantly higher in patients with macroprolactinoma than in those with microadenoma $(p=0.024)$. Patients with hyperprolactinemia due to antipsychotic medication tended to have lower levels of prolactin compared to those with microadenoma, but the difference was not significant. The serum prolactin level in 2 of the 4 patients in this group decreased to normal after cessation of the antipsychotic medication.

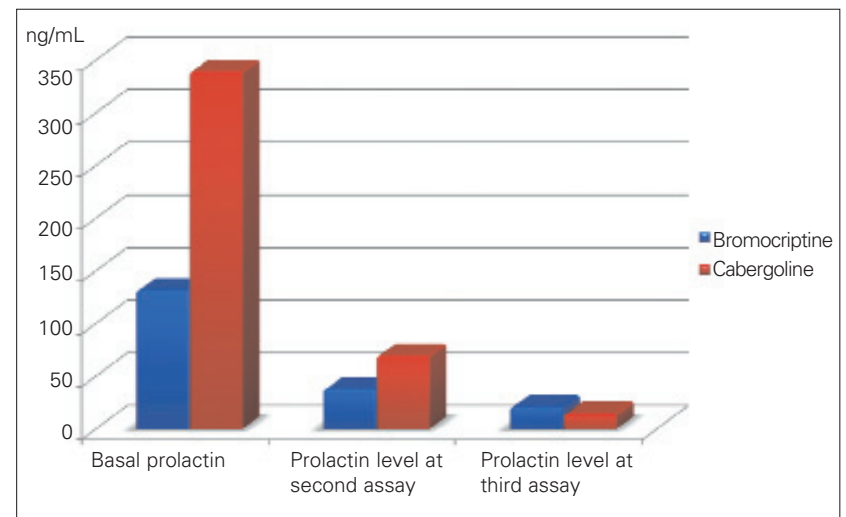

Figure 1. Comparison of effect of prolactin-reducing medications 

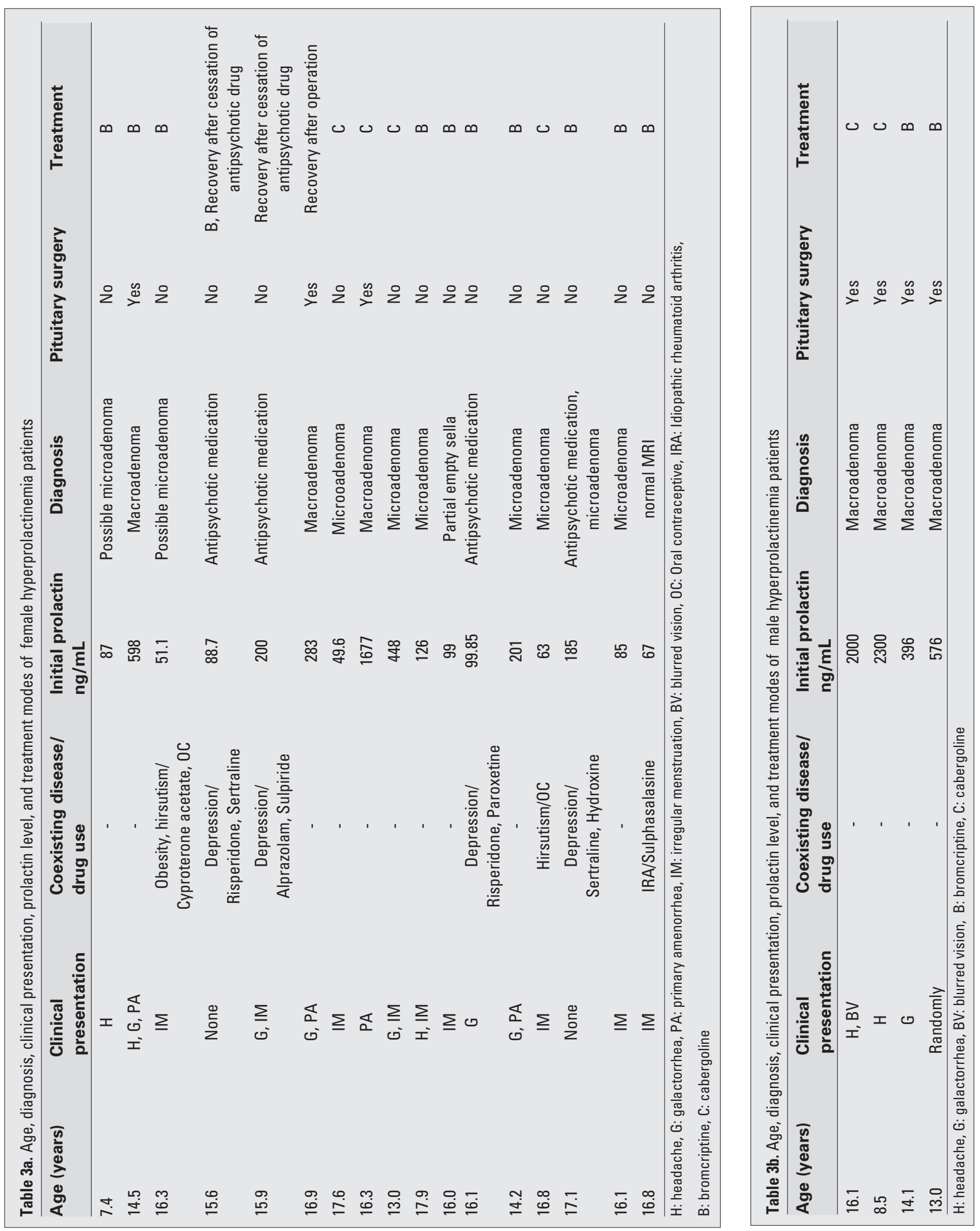
One of the other 2 patients with persistent hyperprolactinemia had microadenoma on MRI, while the second one had normal MRI. Prolactin-lowering medication was continued in both of these patients. MRI revealed microadenoma in 7 , macroadenoma in 7, 'partially empty sella' in 1, and normal pituitary gland in 1 patient. Six of the 7 patients with macroadenoma who had pituitary surgery required medical treatment for persistent postoperative hyperprolactinemia.

Bromocriptine was given to $13(52 \%)$ patients and cabergoline to 6 patients (23\%) as medical treatment. The initial prolactin level was not significantly different between the two groups $(p=0.257)$. The progression of prolactin level in the two treatment groups is demonstrated in Figure 1. Both therapies seemed to be equally efficacious. No significant side effects were observed, except for mild nausea and drowsiness.

\section{Discussion}

Although prolactinoma is the most frequent pituitary adenoma, it is relatively rare in childhood. It usually presents with menstrual problems late in childhood, in adolescent years (6). The clinical signs and symptoms vary according to age, sex, tumor size, and prolactin level. Headache, amenorrhea, and galactorrhea are reported as the major presenting symptoms. Headache is more common in males $(67-77 \%$ vs. $17-30 \%$ in females) and does not seem to be related to the tumor size or prolactin level (7). Seven patients with macroadenoma in our study (all of the 4 male patients and 3 girls) presented with headache. None of the patients had visual problems, except for one who complained of blurred vision that was attributed to myopia. Menstrual irregularity and/or amenorrhea were observed in $76.5 \%$ of our female patients, a finding which was consistent with the literature. Fideleff et al (2) have reported primary amenorrhea in $29-45 \%$ and oligomenorrhea in more than $29 \%$ of their patients. Four of our patients with primary amenorrhea started menstruating after therapy. Galactorrhea has been reported in $30-50 \%$ of the girls with prolactinoma $(2,6)$. Among our patients, $41.2 \%$ (6 girls, 1 boy who also had gynecomastia) had galactorrhea. Saranac et al (8) have studied 11 children with hyperprolactinemia and reported short stature and obesity in 4 . The authors recommended measurement of prolactin levels in short and obese children. In contrast, only 2 of our patients had a height for age below-2SD and only 1 had a BMI value exceeding $+2 S D$.

A number of drugs used in psychiatric clinics lead to an increase in serum prolactin levels. This effect is dosedependent and the elevated serum prolactin returns to normal after the responsible drug is discontinued $(9,10)$. Drug-induced hyperprolactinemia is usually mild $\quad<200$ $\mathrm{ng} / \mathrm{mL}$ ) (5). Among our patients, 4 had drug-induced hyperprolactinemia and one of these patients was also diagnosed to have microadenoma.

Dopamine agonists are the drugs of choice for treatment of micro- and macroadenomas. Bromocriptine, cabergoline, pergolide, and quinagolide inhibit prolactin secretion by exerting G-protein-mediated D2 dopamine agonist effect. Bromocriptine suppresses pituitary mitosis and induces apoptosis and perivascular fibrosis, which lead to diminished tumor size. Bromocriptine is administered twice a day and is notorious for its side effects like nausea, vomiting, postural hypotension, and mental dullness (11). However, our patients tolerated bromocriptine well with no major side effects. Increasing the dose slowly appears to increase tolerability. Cabergoline has an advantage of less frequent dosing and it is reported to be equally effective (6). We also observed that both drugs were efficacious in lowering the prolactin level and did not lead to any significant side effects.

Dopamine agonist therapy per se has been reported to be adequate for macroprolactinoma in adults $(12,13,14)$. However, experience in children is limited. Acharya et al (18) have studied 39 children with hyperprolactinemia including 14 with macroadenoma with suprasellar extension. Dopamine agonist therapy was required in all of the patients postoperatively. Six of the 7 patients with macroadenoma in our study also required dopamine agonist therapy after surgical resection. This finding is in contrast to the remission rates as high as 53-67\% which have been reported in adult studies $(15,16,17)$. However, postoperative hypopituitarism also has been more frequently found in adult studies $(13,14,18)$. No pituitary insufficiency was observed in our patients after surgery. This may suggest that curative surgery requires more extensive resection. However, more extensive resection may also lead to higher rates of postoperative hypopituitarism. In adults, medical therapy is recommended even in patients with a macroadenoma and even in the presence of visual field pathology (19). In children and adolescents, the guidelines are not well defined. We chose to refer the patients for surgery in the presence of macroadenoma. We do not know what the results would have been if medical therapy was initiated. However, we know that surgical therapy alone does not cure and postoperative medical therapy is needed.

In conclusion, patients with hyperprolactinemia, including those with prolactinoma, may present with different symptoms. Any clinical symptom or sign that suggests suppression of the pituitary-gonadal axis must be taken as a reminder for consideration of hyperprolactinemia as a probable diagnosis. Drug-induced hyperprolactinemia may need to be treated with dopamine agonists, but prolactinoma must be excluded. Surgical treatment in children with macroprolactinoma is usually not curative and dopamine agonists must be continued postoperatively. Medical therapy 
may be recommended as first-line treatment for micro-and macroadenoma, but further studies are needed in children.

\section{References}

1. Tetlow LJ, Clayton PE. Tests and normal values in pediatric. In: Brook C, Clayton P, Brown R, editors. Brook's Clinical Pediatric Endocrinology. $5^{\text {th }}$ ed. Blackwell Publishing. 2005;531-532.

2. Fideleff $H L$, Boquete $H R$, Sequera $A$, Suárez $M$, Sobrado $P$, Giaccio A. Peripubertal prolactinomas: clinical presentation and longterm outcome with different therapeutic approaches. J Pediatr Endocrinol Metab 2000:13:261-267.

3. Fideleff $\mathrm{HL}$, Boquete $\mathrm{HR}$, Suarez MG, Azaretzky $\mathrm{M}$. Prolactinoma in Children and Adolescent. Horm Res 2009:72:197-205

4. Vance ML. Hypopituitarism. N Engl J Med 1994;330:1651-1662.

5. Goffin V, Binart N, Touraine P, Kelly PA. Prolactin: the new biology of an old hormone. Ann Rev Physiol 2002;64:47-67.

6. Colao A, Loche S, Cappa M, Di Sarno A, Landi ML, Sarnacchiaro F, Facciolli G, Lombardi G. Prolactinomas in children and adolescents. Clinical presentation and long-term follow-up. J Clin Endocrinol Metab 1998;83:2777-2780.

7. Kane LA, Leinung MC, Scheithauer BW, Bergstralh EJ, Laws ER Jr, Groover RV, Kovacs K, Horvath E, Zimmerman D. Pituitary adenomas in childhood and adolescence. J Clin Endocrinol Metab 1994;79:1135-1140.

8. Saranac L, Zivanovic S, Radovanovic Z, Kostic G, Markovic I, Miljkovic P. Hyperprolactinemia: different clinical expression in childhood. Horm Res Paediatr 2010;73:187-192.

9. Wudarsky $M$, Nicolson $R$, Hamburger SD, Spechler $L$, Gochman P, Bedwell J, Lenane MC, Rapoport JL. Elevated prolactin in pediatric patients on typical and atypical antipsychotics. J Child Adolesc Psychopharmacol 1999:9:239-245.

10. Correll CU, Carlson HE. Endocrine and metabolic adverse effects of psychotropic medications in children and adolescents. J Am Acad Child Adolesc Psychiatry 2006;45:771-791.
11. Vance ML, Evans WS, Thorner MO. Drugs five years later: bromocriptine. Ann Intern Med 1984;100:78-91.

12. Colao A, Di Sarno A, Landi ML, Cirillo S, Sarnacchiaro F, Facciolli G, Pivonello R, Cataldi M, Merola B, Annunziato L, Lombardi G. Long-term and low-dose treatment with cabergoline induces macroprolactinoma shrinkage. J Clin Endocrinol Metab 1997; 82:3574-3579.

13. Kars M, Pereira AM, Smit JW, Romijn JA. Long-term outcome of patients with macroprolactinomas initially treated with dopamine agonists. Eur J Intern Med 2009;20:387-393.

14. Iglesias P, D'ez JJ. Complete remission of macroprolactinoma after long-term medical therapy with dopamine agonists. QJM 2010 Jul 27. [Epub ahead of print]

15. Raverot G, Wierinckx A, Dantony E, Auger C, Chapas G, Villeneuve L, Brue T, Figarella-Branger D, Roy P, Jouanneau $E$, Jan M, Lachuer J, Trouillas J; HYPOPRONOS. Prognostic factors in prolactin pituitary tumors: clinical,histological, and molecular data from a series of 94 patients with a long postoperative follow-up. J Clin Endocrinol Metab 2010:95:1708-1716.

16. Hamilton DK, Vance ML, Boulos PT, Laws ER. Surgical outcomes in hyporesponsive prolactinomas: analysis of patients with resistance or intolerance to dopamine agonists. Pituitary 2005;8:53-60.

17. Kreutzer J, Buslei R, Wallaschofski H, Hofmann B, Nimsky C, Fahlbusch R, Buchfelder M. Operative treatment of prolactinomas: indications and results in a current consecutive series of 212 patients. Eur J Endocrinol 2008;158:11-18.

18. Acharya SV, Gopal RA, Bandgar TR, Joshi SR, Menon PS, Shah NS. Clinical profile and long term follow up of children and adolescents with prolactinomas. Pituitary 2009;12:186-189.

19. Diagnosis and treatment of hyperprolactinemia: An Endocrine Society Clinical Practice Guideline. J Clin Endo Metab 2011;96:273-288. 